\title{
Study on the intensity of radiation attenuated by protective barriers in diagnostic $\mathrm{X}$-ray installations
}

\author{
Jonathan Lalrinmawia ${ }^{1,2}$, Kham Suan Pau' ${ }^{2}$, Ramesh Chandra Tiwari ${ }^{1 *}$ \\ ${ }^{1}$ Department of Physics, Mizoram University, Aizawl 796004, Mizoram, India \\ ${ }^{2}$ Mizoram State Cancer Institute, Zemabawk, Aizawl 796017, Mizoram, India
}

\begin{abstract}
The main objective of the present study is to find out the intensity of radiation attenuated by different types of patient entrance doors (PED) as well as control panel (CP) protective barriers in diagnostic $X$-ray installations. To measure the intensity of ionizing radiation, ion chamber survey meter was used; all measurements were performed in freeze mode. In setting maximum accelerating potential, minimum tube current and fixed exposure time, a water phantom was exposed through maximum field size. Radiation exposure rates were measured at CPs as well as PEDs with and without barriers. In chest mission, radiation rates with PED ranged from $0.3 \mu \mathrm{Sv} / \mathrm{h}$ to $0.7 \mathrm{mSv} / \mathrm{h}$ and without PED $0.2 \mathrm{mSv} / \mathrm{h}$ to $1.2 \mathrm{mSv} / \mathrm{h}$. At the same time, in couch mission, radiation rates measured behind PED ranged from $0.3 \mu \mathrm{Sv} / \mathrm{h}$ to $2.2 \mathrm{mSv} / \mathrm{h}$ and $0.03 \mathrm{mSv} / \mathrm{h}$ to $2.25 \mathrm{mSv} / \mathrm{h}$ in front of PED. All institutions showed higher exposure rates without PED; all types of doors considerably attenuated radiation. Among different types of door, lead-lined door attenuated $99.53 \%$ in chest mission and $97.44 \%$ in couch mission. While plywood doors attenuated approximately $40 \%$ of the incident radiation, it is more or less similar as air does in every half meter away from the phantom. Radiation rates in chest missions with CP barriers ranged from $2 \mu \mathrm{Sv} / \mathrm{h}$ to $0.38 \mathrm{mSv} / \mathrm{h}$, while $0.4 \mathrm{mSv} /$ $\mathrm{h}$ to $2.35 \mathrm{mSv} / \mathrm{h}$ without $\mathrm{CP}$ barriers. In couch missions, radiation rates measured with $C P$ barriers varied from $4 \mu \mathrm{Sv} / \mathrm{h}$ to $0.6 \mathrm{mSv} / \mathrm{h}$ whereas without $\mathrm{CP}$ barriers from $0.7 \mathrm{mSv} / \mathrm{h}$ to $5 \mathrm{mSv} / \mathrm{h}$. There was a significant difference between radiation measured behind and in front of the CP barriers. Among them, the percentage of attenuation was high in lead and concrete barriers.
\end{abstract}

Keywords: Attenuation, diagnostic X-ray, patient entrance door, protective barrier, radiation safety

\section{Introduction}

Among radiation workers, the risk of solid cancers increases significantly as cumulative radiation exposure increased. ${ }^{1}$ However, proper use of protective barrier in Control Panel (CP) and Patient Entrance Door (PED) significantly reduces radiation dose at CP and outside PED. ${ }^{2,3}$ In the present study area only $11.2 \%$ installations employs lead-lined door and $40.82 \%$ employs CP barrier with lead glass. ${ }^{4}$ Others installed solid wood, plywood, aluminium plane sheet, concrete material for PED barrier as well as CP barrier. Therefore, it is very important to know the safety status of these different kinds of shielding materials and compare with lead material in terms of radiation safety. Archer ${ }^{5}$ reported that other materials can be used to complement or replace lead and concrete as an effective barrier against diagnostic energy $\mathrm{X}$-rays. 
It is well known that X-ray photons are formed by the interaction of accelerated electrons with matter at the atomic level. These photons lose their lives by transferring their energy to electrons contained in matter. ${ }^{6}$ When a photon interacts with matter, it either absorbs or changes energy and/or direction of motion. ${ }^{7}$ To calculate photon attenuation by any thickness of material, equation 1 is mainly used. However, it is precise only when the attenuation coefficient is constant; all the photons in the incident beam have same energy (a mono-energetic beam) plus the beam is narrow.

$$
N=N_{o} e^{-\mu x}
$$

where, $\mu$ - constant of proportionality called linear attenuation coefficient $\left(\mathrm{m}^{-1}\right)$

$N$ - no. of transmitted photon by any thickness ' $x$ '

$N_{o}$ - the no. of incident photons

$e$ - base of natural logarithms with values $2.718^{8,9}$

So, using equation (1) only non-collided photons can be considered but while using equation (2), collided photons which scattered from various points in the shield are included. The radiation transmitted with a broad beam is greater than that implied simply by the linear attenuation coefficient.

$$
N=N_{0} e^{-\mu x} B
$$

where, $B$ is a photon build-up factor that takes account of the photons scattered by the attenuator. The value of $B$ is never less than unity and depends on specific quantity under consideration, such as exposure, intensity, or absorbed dose. . $^{8,10}$

The interaction of $\mathrm{X}$-rays with matter involves three important mechanisms: photoelectric absorption, coherent-incoherent scattering and pair production. ${ }^{8}$ In diagnostic radiology, only photoelectric effect, coherence and incoherence scattering are considered because energy up to 150 $\mathrm{kVp}$ is employed. ${ }^{11}$ In the photoelectric process, an incident photon having energy $h v$ is absorbed by an atom. The photon disappears, and electron is ejected from the atom. Photoelectric absorption is the dominant mode of attenuation for low-energy photons and high atomic number $(Z)^{8,10}$ The photoelectric effect accounts for most of the attenuation of low-energy photons, however its influence falls quickly with increasing energy. At the same time, the probability for Compton scattering process increases. In the process of Compton scattering, only a portion of the energy is absorbed and a photon is produced with reduced energy in a direction different from that of the original photon. Increasing primary photon energy causes a general shift of scatter in the forward direction. However, in diagnostic procedures, there is always a significant amount of back and side-scatter radiation. ${ }^{6}$ At intermediate energies, the Compton scattering is the dominant mode of attenuation for all $Z$. For compounds and mixtures of materials, the attenuation coefficients are assumed to be the sum of the individual, independent atomic contributions. $^{10}$

It is very difficult to predict precisely either how far a photon will travel before it engaged in an interaction or the type of interaction it will engage in. However, in most cases, people are interested in the overall rate at which photons interact as they make their way through a specific material. ${ }^{6}$ To find out the thickness of matter required to reduce a given photon field to some desired level, shielding calculations can be done. Computations are also made to determine how much a given shield attenuated the radiation, mainly based on equation 1. The intention of the present study is to assess the safety status of different kinds of shielding materials by evaluating and comparing the amount of intensity of radiation attenuated by different types of patient entrance doors as well as control panel barriers.

\section{Materials and Methods}

After surveying all the conventional diagnostic Xray installations in Aizawl, Mizoram, India, the authors selected ten units installed in ten different institutions. Diagnostic X-ray equipment's were selected based on the following criteria: fixed and mobile-fixed X-ray machines, presently used for both couch and chest X-ray examinations; Atomic Energy Regulatory Board (AERB) type approved unit having PED (lead-lined, wooden, plywood, etc.) and CP protective barrier (lead, concrete, plywood, etc.); maximum rating of the $\mathrm{X}$-ray unit (current, potential and exposure time); accuracy of focus to table top distance; accuracy of tube orientation indication; collimator adjustment.

The survey instrument used to measure stray radiation is a pressurized ion chamber-based survey meter - model 451 P (Fluke Biomedical, 6920 Seaway Blvd., Everett, WA, USA). The calibration measurements are traceable to the national institute of standards and technology (NIST, Gaitherberg, MD, USA). The response time of the survey meter is $5 \mathrm{~s}$ for $0 \mu \mathrm{Sv} / \mathrm{h}$ to $5 \mu \mathrm{Sv} / \mathrm{h} ; 2 \mathrm{~s}$ for $0 \mu \mathrm{Sv} / \mathrm{h}$ to $50 \mu \mathrm{Sv} / \mathrm{h}$; $1.8 \mathrm{~s}$ for $0 \mathrm{mSv} / \mathrm{h}$ to $5 \mathrm{mSv} / \mathrm{h}$. The survey meter has accuracy $\pm 10 \%$ of reading between $10 \%$ and $100 \%$ of full-scale indication on any range with precision within $5 \%$ reading. ${ }^{11}$ Sketches were made for every $X$ -ray installation indicating $X$-ray source, couch, chest stand, protective barrier, $C P$, and PED. Distances of $\mathrm{CP}$ from couch and chest stands along with PED from couch and chest stands were measured (in $\mathrm{cm}$ ) and recorded (Fig. 1). In the present study, the protective barriers at CP were lead-lined, concrete, plywood and plywood plane sheet-lined. At the same time PED were lead-lined, solid wood, plywood and plywood plane sheet-lined. A water phantom, 


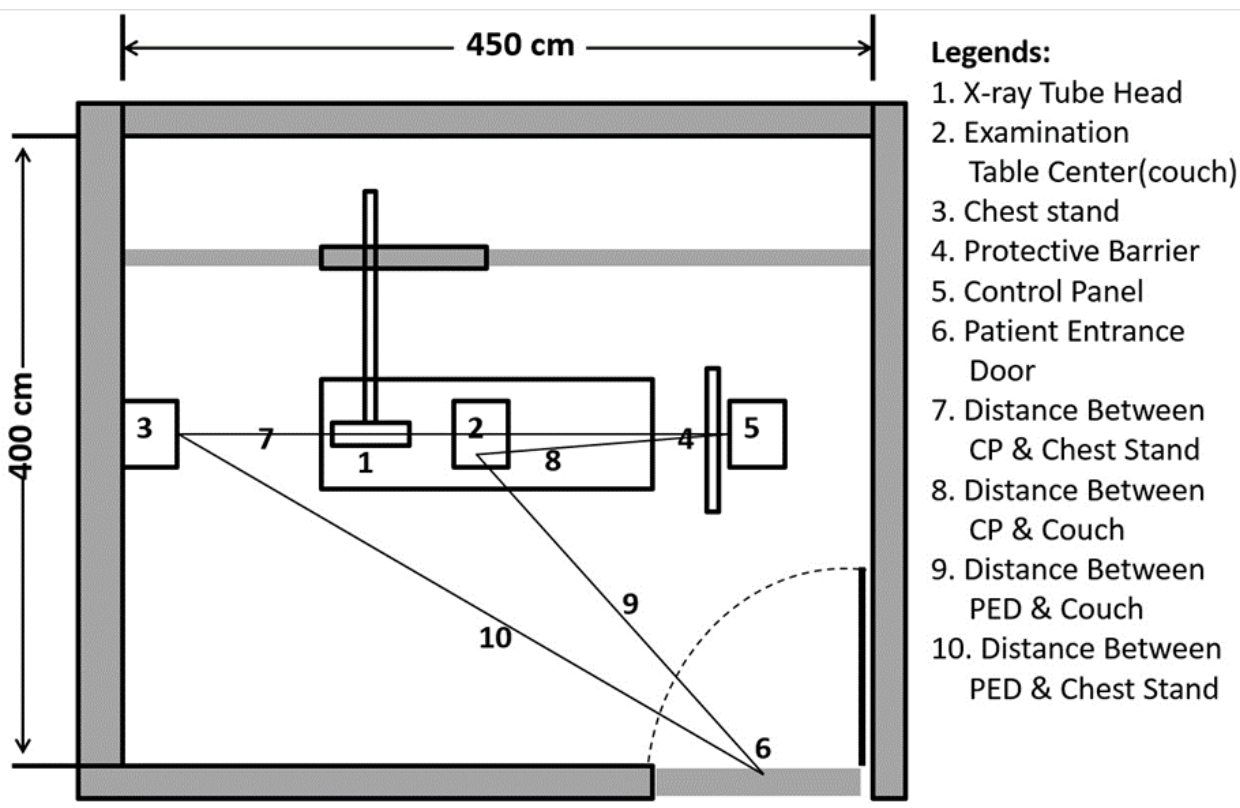

Figure 1 | Layout of diagnostic $\mathrm{X}$-ray installation room.

ten litres of fresh water in a plastic container was used as source of scattered which was positioned on a couch for vertical exposure (couch mission) and at chest stand for horizontal exposure (chest mission). The plastic container is a perfect cube where all the sides; length, width and height are equivalent, i.e. 31 $\mathrm{cm}$ each respectively. The thickness of this container is $1 \mathrm{~cm}$ and it is uniform throughout the body (Fig. 2). Field sizes were adjusted to maximum and focused at the water phantom. Exposure rates were measured at the $\mathrm{CP}$ with and without barrier; at the PED with door open and close.

The intensity of radiation (with and without door/ barrier) at CP and outside PED were measured by setting maximum accelerating potential and minimum current with fixed exposure time as shown in Table $1.2,3,13$ The survey meter was placed at a height with respect to the phantom base with its measuring surface in the direction of the phantom. ${ }^{14}$ In this set up, the survey meter could measure radiations scattered from the phantom, the walls, the floor and the ceiling as well as leakage radiation from the tube housing. ${ }^{15}$ All the measurements were

Table 1 | Input parameters settings for stray radiation rate measurement.

\begin{tabular}{lll}
\hline \multicolumn{1}{c}{ Parameters } & Set value & \multicolumn{1}{c}{$\begin{array}{c}\text { As per } \\
\text { reference }\end{array}$} \\
\hline Accelerating Potential & 80 to $120 \mathrm{kV}$ & Maximum kV \\
\hline Current & 20 to $80 \mathrm{~mA}$ & Minimum mA \\
\hline Time & $1 \mathrm{~s}$ & Fixed \\
\hline
\end{tabular}

performed in freeze mode. For calculating mean, range and standard deviation (SD), SPSS statistics for Windows, Version 17.0 (SPSS, Inc., Chicago, IL, USA) was used. $t$-test was used to check the significance difference between radiation level measured with and without CP barrier as well as PED in chest and couch missions.

\section{Results and Discussion}

\section{Attenuation of PED}

The quantity of stray radiation rates outside PED in chest and couch mission are shown in figure 3. These intensities of radiation were measured in closed PED as well as open PED. In chest mission, radiation rates with $\mathrm{PEDs}$ ranged from $0.3 \mu \mathrm{Sv} / \mathrm{h}$ $(0.03 \mathrm{mR} / \mathrm{h})$ to $0.7 \mathrm{mSv} / \mathrm{h}(70 \mathrm{mR} / \mathrm{h})$ with a mean of $0.19 \mathrm{mSv} / \mathrm{h}(18.95 \mathrm{mR} / \mathrm{h})$, whereas radiation rates without PEDs varied from $0.02 \mathrm{mSv} / \mathrm{h}(2.1 \mathrm{mR} / \mathrm{h})$ to $1.2 \mathrm{mSv} / \mathrm{h}(120 \mathrm{mR} / \mathrm{h})$ with mean $0.55 \mathrm{mSv} / \mathrm{h}(54.96$ $\mathrm{mR} / \mathrm{h}$ ). At the same time, in couch mission, radiation

Table 2 | Difference between exposure rates measured with and without patient entrance doors (PEDs) in chest and couch missions.

\begin{tabular}{llcccc}
\hline Mission & \multicolumn{1}{c}{ PED } & N & Mean & $\begin{array}{c}\text { t } \\
\text { value }\end{array}$ & $\begin{array}{c}\boldsymbol{p} \\
\text { value }\end{array}$ \\
\hline $\begin{array}{l}\text { Chest } \\
\text { Mission }\end{array}$ & With PED & 10 & 18.95 & 3.09 & 0.05 \\
\cline { 2 - 6 } Couch & Without PED & 10 & 54.96 & & \\
Mission & With PED & 10 & 43.44 & 3.16 & 0.05 \\
\cline { 2 - 5 } & Without PED & 10 & 74.73 & &
\end{tabular}




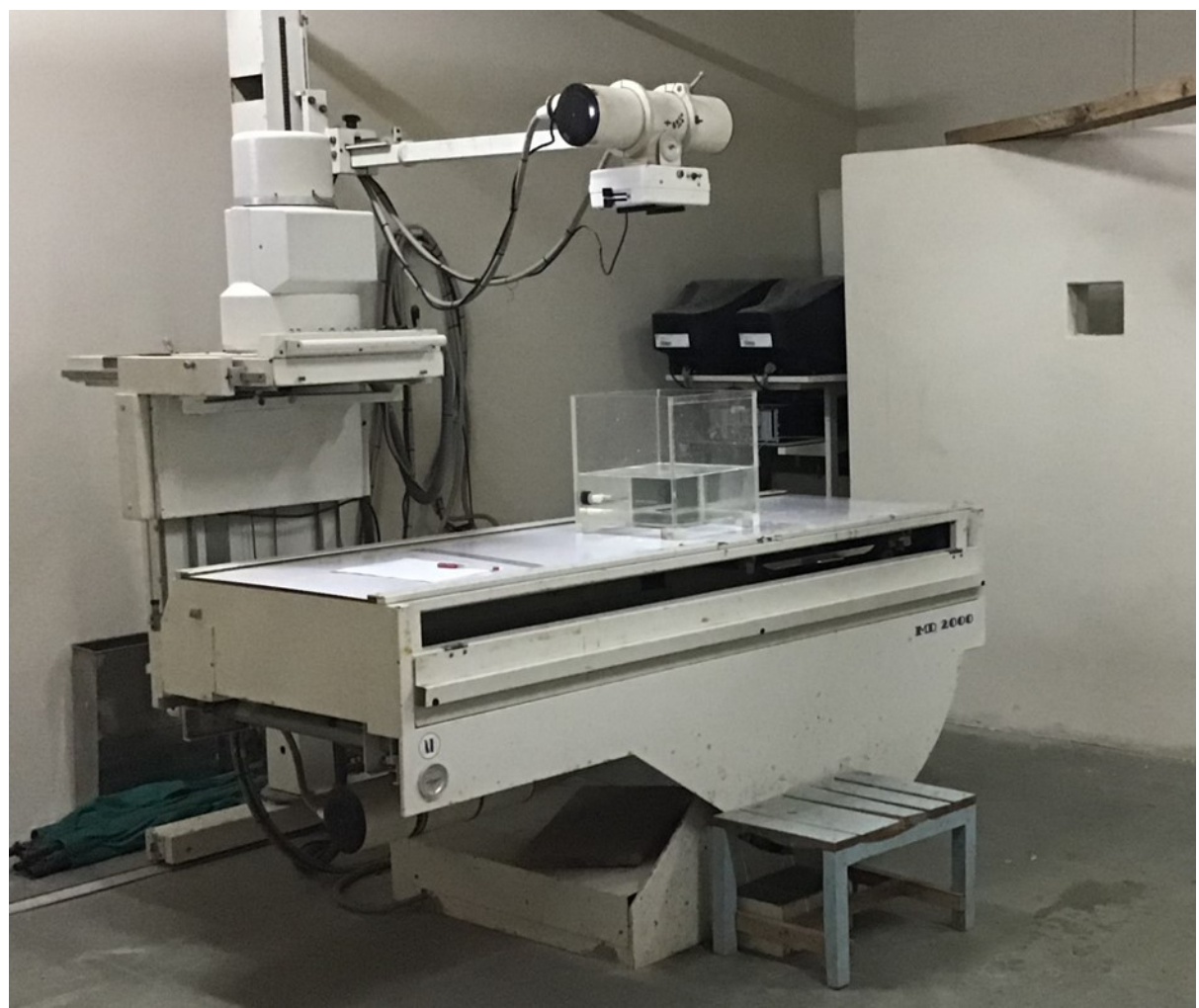

Figure 2 | A water phantom setting for vertical exposure (couch mission).

Table 3 | Attenuation (percentage) of different types of patient entrance door.

\begin{tabular}{clccc}
\hline $\begin{array}{c}\text { Expt. } \\
\text { Unit No. }\end{array}$ & Type of Door & Thickness $\mathbf{( c m )}$ & $\begin{array}{c}\text { Percentage of } \\
\text { attenuation (Chest } \\
\text { Mission) }\end{array}$ & $\begin{array}{c}\text { Percentage of } \\
\text { attenuation (Couch } \\
\text { Mission) }\end{array}$ \\
\hline 10 & Solid wood & 3.2 & 99.81 & 99.61 \\
\hline 6 & Solid wood & 3.8 & 98.33 & 98.75 \\
\hline 1 & Solid wood & 3.3 & 41.67 & 25.00 \\
\hline 2 & Solid wood & 3.5 & 30.91 & 41.67 \\
\hline 9 & Plywood & 0.5 & 40.00 & 02.50 \\
\hline 3 & Plywood & 0.3 & 39.13 & 02.22 \\
\hline 8 & Plywood & 0.3 & 57.78 & 81.82 \\
\hline 5 & Plywood & 0.3 & 54.55 & 26.32 \\
\hline 7 & Plywood plane sheet-lined & $1, .3$ & 85.00 & 95.00 \\
\hline 4 & Wood lead-lined & 4.0 & 99.53 & 97.44 \\
\hline
\end{tabular}

rates measured behind PEDs ranged from $0.3 \mu \mathrm{Sv} / \mathrm{h}$ $(0.03 \mathrm{mR} / \mathrm{h})$ to $2.2 \mathrm{mSv} / \mathrm{h}(220 \mathrm{mR} / \mathrm{h})$ with mean 0.43 $\mathrm{mSv} / \mathrm{h}(43.44 \mathrm{mR} / \mathrm{h})$. Similar case is also seen in case of couch mission where radiation rates without PEDs was higher, $0.03 \mathrm{mSv} / \mathrm{h}(2.8 \mathrm{mR} / \mathrm{h})$ to $2.25 \mathrm{mSv} / \mathrm{h}$ (225 mR/h) with mean $0.75 \mathrm{mSv} / \mathrm{h}(74.73 \mathrm{mR} / \mathrm{h})$. It is comprehensible from figure 3 that all the institutions showed higher radiation rates in the absence of PED. It means that all types of door attenuated the incident ionizing radiation noticeably by the process of photoelectric effect and Compton scattering. However, the amount of attenuation produced by different types of door was not similar because interaction process between $\mathrm{X}$-ray and lead-lined
Table 4 | Difference between exposure rates measured with and without $\mathrm{CP}$ barriers in chest and couch missions.

\begin{tabular}{llllll}
\hline Mission & \multicolumn{1}{c}{ CP Barrier } & N & Mean & $\begin{array}{c}\mathbf{t} \\
\text { value value }\end{array}$ \\
\hline Chest & With barrier & 10 & 10.56 & 4.25 & 0.01 \\
Mission & Without barrier & 10 & 113.1 & & \\
Couch & With barrier & 10 & 17.21 & 5.49 & 0.01 \\
Mission & Without barrier & 10 & 266.5 & & \\
\hline
\end{tabular}


Table 5 | Attenuation (percentage) of different types of control panel barrier.

\begin{tabular}{clccc}
\hline $\begin{array}{c}\text { Expt. } \\
\text { Unit No. }\end{array}$ & \multicolumn{1}{c}{ Type of Barrier } & $\begin{array}{c}\text { Thickness } \\
\text { (cm) }\end{array}$ & $\begin{array}{c}\text { Percentage of } \\
\text { attenuation (Chest } \\
\text { Mission) }\end{array}$ & $\begin{array}{c}\text { Percentage of } \\
\text { attenuation (Couch } \\
\text { Mission) }\end{array}$ \\
\hline 5 & Lead-lined & 0.4 & 99.83 & 99.42 \\
\hline 3 & Lead-lined & 2.5 & 99.09 & 99.77 \\
\hline 1 & Wood Lead-lined & 2 & 98.53 & 92.86 \\
\hline 4 & Lead-lined & 0.3 & 99.83 & 99.86 \\
\hline 6 & Wood Lead-lined & $0.1,2.6$ & 99.03 & 98.81 \\
\hline 10 & Lead-lined & 2 & 99.43 & 99.57 \\
\hline 9 & Plywood & 0.3 & 20.00 & 76.67 \\
\hline 7 & Plywood plane sheet-lined & $0.1,0.3$ & 80.00 & 87.50 \\
\hline 2 & Concrete & 25 & 99.66 & 99.81 \\
\hline
\end{tabular}

door will be different from X-ray and plywood door and so on. In addition to that, in the present study there was a significant difference $(0.05$ level) between radiation measured with and without PED in chest and couch missions (Table 2).

Percentage of attenuation, attenuated by different types of door i.e. solid wood, plywood, plywood-plane sheet-lined and lead-lined doors with respect to distances are shown in Figure 4. The thickness of each type of door as well as their respective attenuation percentage is given in Table 3. Among different types of door, lead-lined door attenuated radiation in large amount $(99.53 \%$ in chest mission and $97.44 \%$ in couch mission) because they have a greater number of atoms in a unit area. ${ }^{16}$ However, the authors believed that installation layout, distance between source of radiation and shielding etc. plays a very important role because solid wood having almost the same thickness has extensive different amount of attenuation. The solid wooden PED ( ${ }^{1}$ Fig. 3) which showed a good attenuation property was installed behind $\mathrm{CP}$ protective barrier for both chest and couch missions. Further, the other wooden door $\left({ }^{{ }^{2}}\right.$ Fig. 3) was installed in a large room, where distance between chest stand and PED in chest mission was $790 \mathrm{~cm}$; $430 \mathrm{~cm}$ between couch and PED in couch mission, simultaneously the PED installed almost behind $C P$ barrier. Among the PEDs, even lead-lined door cannot attenuate $100 \%$ of the incident radiation. Which is clear from the equation 1, i.e. $N=N_{o} e^{-\mu x}$ that there will always be a photon which transmit at any thickness without having interaction. ${ }^{9,10}$ While plywood doors attenuated approximately $40 \%$ of the incident radiation, it is almost same as air does in every half meter away from the phantom. ${ }^{14}$

\section{Attenuation of CP Barrier}

The amount of stray radiation rates behind and in front of Control Panel (CP) protective barriers are shown in figure 5 . Radiation rates in chest missions with barriers ranged from $2 \mu \mathrm{Sv} / \mathrm{h}(0.2 \mathrm{mR} / \mathrm{h})$ to 0.38 $\mathrm{mSv} / \mathrm{h}(38 \mathrm{mR} / \mathrm{h})$ with mean $0.11 \mathrm{mSv} / \mathrm{h}(10.56 \mathrm{mR} /$ h), while $0.4 \mathrm{mSv} / \mathrm{h}(40 \mathrm{mR} / \mathrm{h})$ to $2.35 \mathrm{mSv} / \mathrm{h}(235$ $\mathrm{mR} / \mathrm{h})$ with mean $1.13 \mathrm{mSv} / \mathrm{h}(113.1 \mathrm{mR} / \mathrm{h})$ without barrier. In couch missions, radiation rates measured with barriers varied from $4 \mu \mathrm{Sv} / \mathrm{h}(0.4 \mathrm{mR} / \mathrm{h})$ to 0.6 $\mathrm{mSv} / \mathrm{h}(60 \mathrm{mR} / \mathrm{h})$ with mean $0.17 \mathrm{mSv} / \mathrm{h}(17.21 \mathrm{mR} /$ h), whereas without barrier it varied from $0.7 \mathrm{mSv} / \mathrm{h}$ $(70 \mathrm{mR} / \mathrm{h})$ to $5 \mathrm{mSv} / \mathrm{h}(500 \mathrm{mR} / \mathrm{h})$ with mean 2.66 $\mathrm{mSv} / \mathrm{h} \quad(266.5 \mathrm{mR} / \mathrm{h})$. There exists a significant difference $(0.01$ level) between radiation measured with and without $C P$ barriers in chest and couch missions. Except for plywood and plywood plane sheet-lined barrier, all other barriers, i.e. lead and concrete were showing a good barrier property, the reason is same as in the case of PED. While all the barriers attenuated radiation, the amount of attenuation was not the same in different barriers mainly due to different scattering mechanism and barrier's physical property. Even though the same input parameters were applied, amount of attenuation for same material was different due to different installation layout, space, tube efficiency.

Percentages of attenuation, attenuated by different types of protective barrier with respect to distance are shown in Figure 6. Among different barriers, lead and concrete barriers attenuated more than $90 \%$ of incident radiation (Table 5). However, plywood and plywood-plane sheet-lined barriers attenuated relatively lesser amount of radiation. As already mentioned, lead and concrete are denser than plywood and thicker in the present study. At the same time the effect of tube efficiency, distance, and installation layout could not be controlled as the authors studied the real situation of barrier in different X-ray installations. Even though plywood plane sheet-lined barrier attenuated few portions of incident radiation, it is not recommended because the amount of stray radiation measured on $\mathrm{CP}$ is considerable and the person behind the barrier is the radiation worker who performed every examination. 


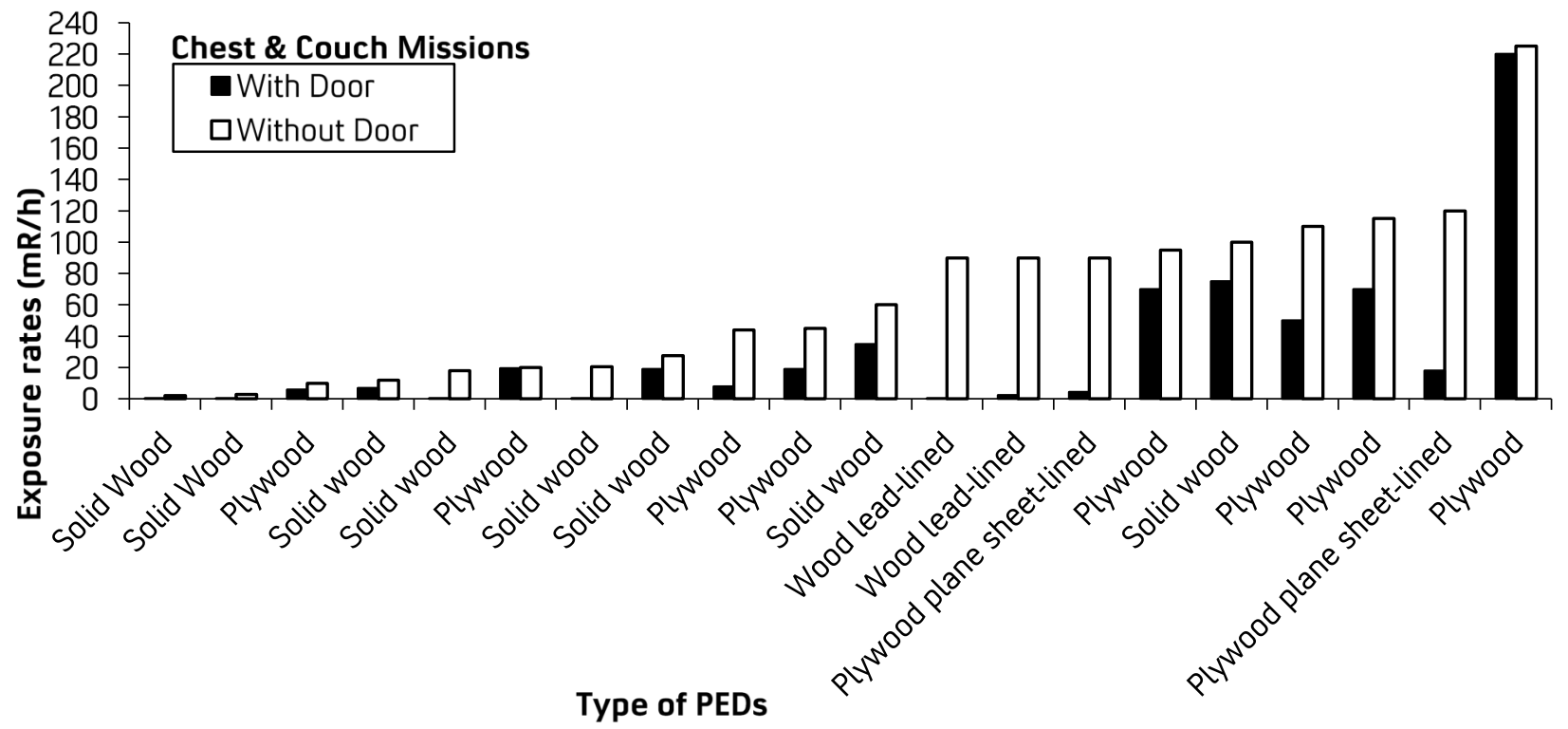

Figure 3 | Exposure rates measured outside PEDs with door open and close in chest and couch missions.

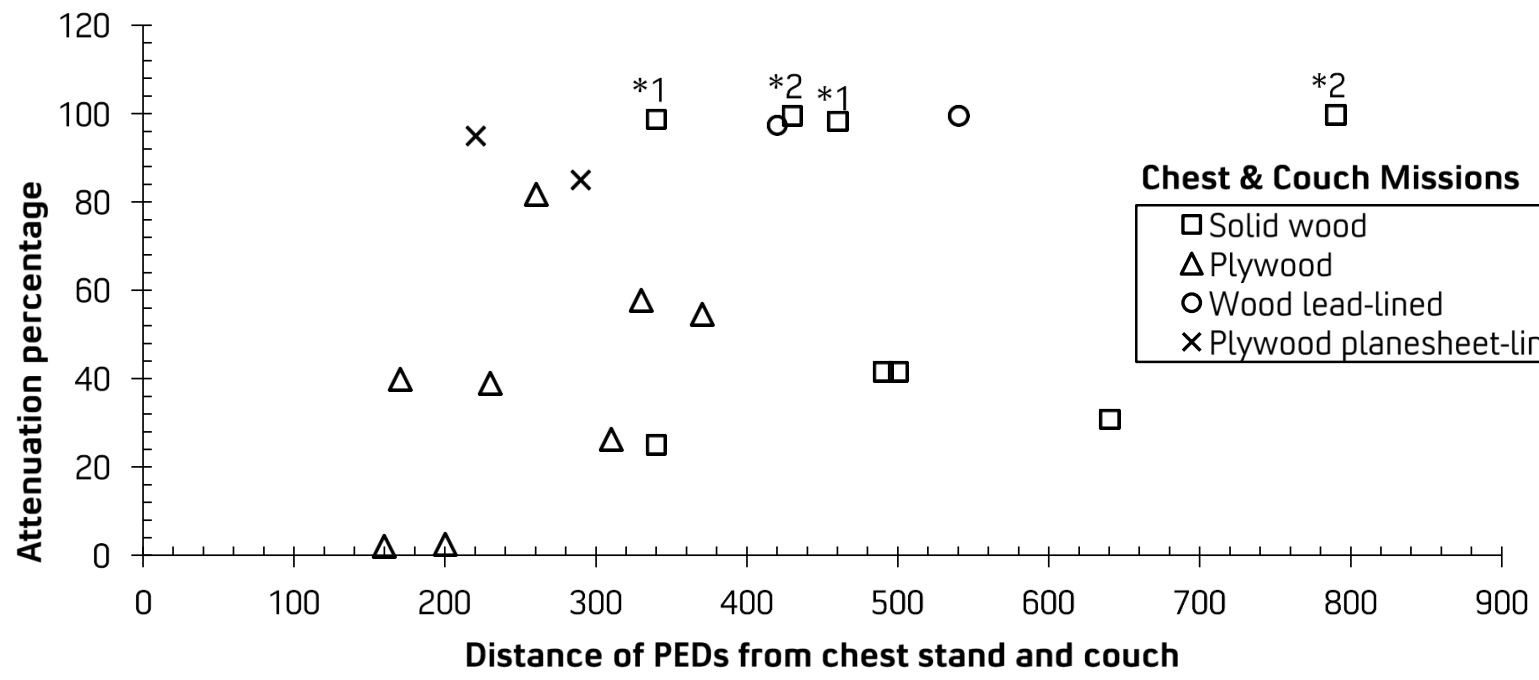

Figure 4 | Percentage of attenuation; attenuated by solid wood, plywood, lead and plywood-plane sheet-lined door.

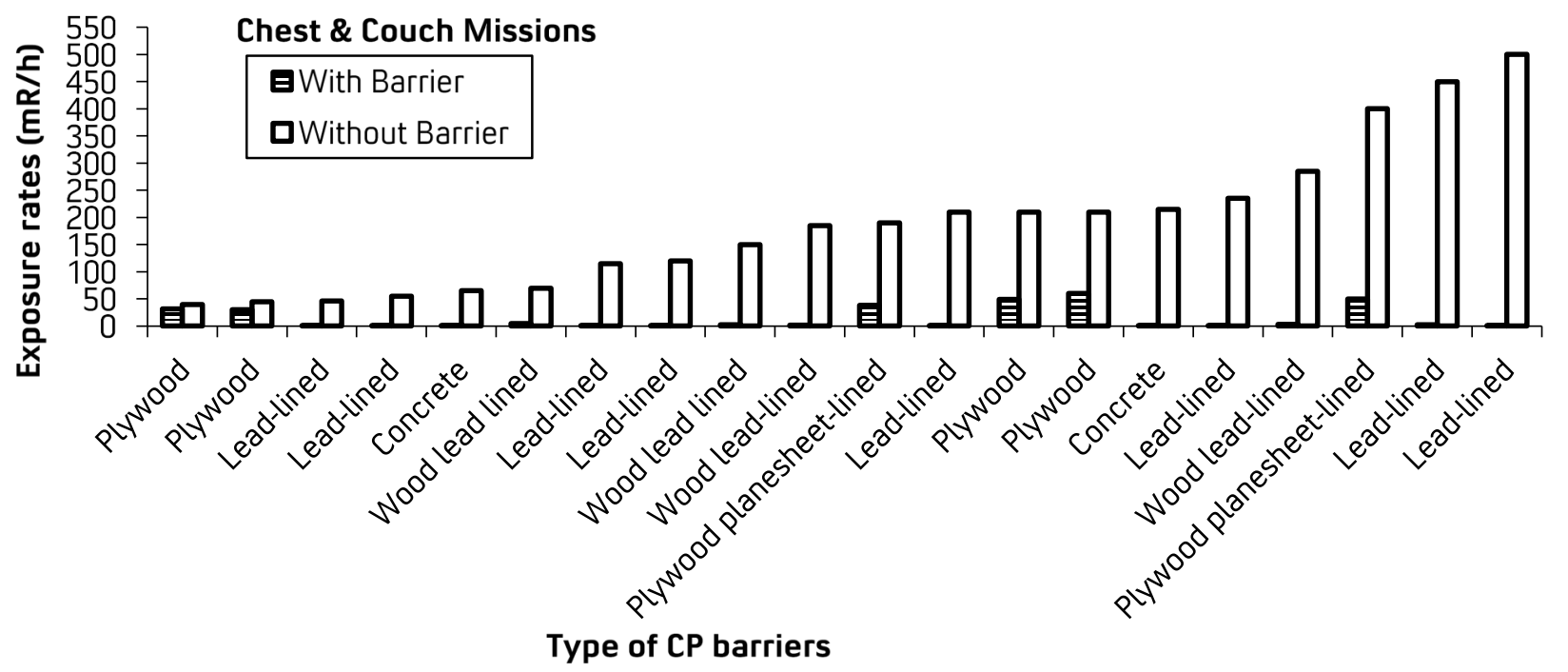

Figure $\mathbf{5}$ | Exposure rates measured at CPs with and without barriers in chest and couch missions. 


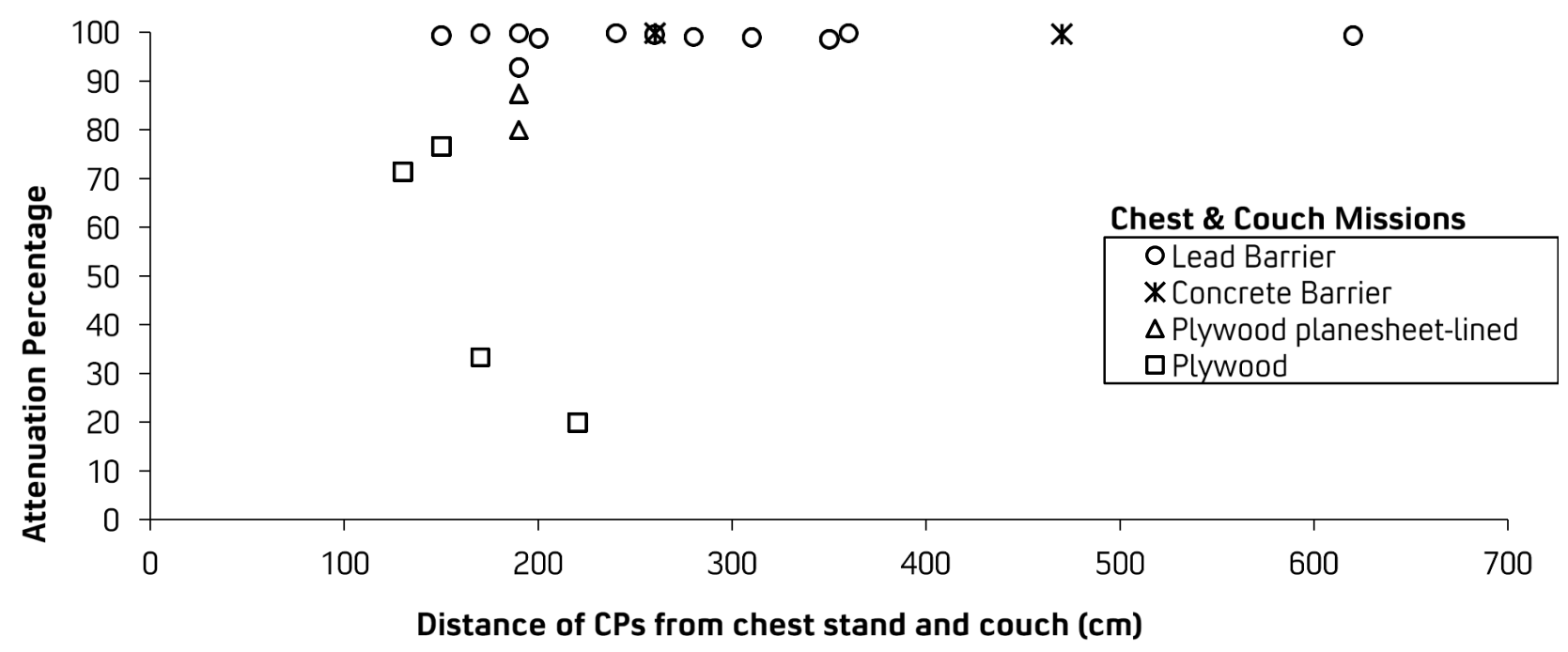

Figure 6 | Percentage of attenuation; attenuated by lead, concrete, plywood and plywood-plan sheet-lined barriers.

\section{Conclusion}

It was found that each type of PED attenuated radiation but in different quantity where lead-lined door attenuated relatively large amount $(>90 \%$ in chest and couch missions). Installing plywood and plywood-plane sheet-lined door is healthier than no door at all because it attenuated considerable amount of radiation. On the other hand, patient entrance door which can reduce any type of stray radiation below a level of $1 \mathrm{mSv} \mathrm{y}^{-1}$ is recommended. ${ }^{17}$ Again, $\mathrm{CP}$ protective barriers attenuated significant amount of incident radiation. Among them, lead and concrete barriers attenuated more than $90 \%$ of incident radiation while plywood plane sheet-lined barrier attenuated relatively lesser quantity.

\section{Conflicts of Interest}

None declared.

\section{References}

1. Sun, Z., Inskip, P.D., Wang, J., Kwon, D., Zhao, Y. \& Zhang, L. (2016). Solid cancer incidence among Chinese medical diagnostic X-ray workers, 19501995: Estimation of radiation-related risks. International Journal of Cancer, 138, 2875-2883. doi: 10.1002/ijc.30036

2. Lalrinmawia, J., Pau, K.S. \& Tiwari, R.C. (2017). Investigations of workers dose due to stray radiation in X-ray installations in Mizoram. In Recent Advances in Physics Research and its Relevance, Excel India publishers, New Delhi, pp. 258-263.

3. Lalrinmawia, J., Pau, K.S. \& Tiwari, R.C. (2017).
Investigations of public dose due to stray radiation in X-ray installations in Mizoram. In Science and Technology for Shaping the Future of Mizoram. Allied publishers Pvt. Ltd., New Delhi, pp. 305-309.

4. Lalrinmawia, J., Pau, K.S. \& Tiwari, R.C. (2017). Quality Assurance Assessment of Conventional Diagnostic X-ray Installations in Mizoram. Journal of Medical Physics, 42, Suppl S1, 208-209. http:// www.jmp.org.in/text.asp?2017/42/5/110/217113

5. Archer, B.R. (1994). Attenuation properties of diagnostic x-ray shielding materials. Medical Physics, 21(9), 1499-1507. doi: 10.1118/1.597408

6. Sprawls, P. (2017). Interaction of Radiation with Matter. sprawls.org/ppmi2/INTERACT (5 April 2019).

7. Carlsson, C.A. \& Carlsson, G.A. (1996). Basic Physics of X-ray Imaging (2n edition). Linkoping University, Sweden.

8. Johns, H.E. \& Cunningham, J.R. (1983). The Physics of Radiology (4th edition). Springfield, Illinois 62717, USA. Thomas C. C., Publisher, pp. 133-164.

9. Lalrinmawia, J., Pau, K.S. \& Tiwari, R.C. (2018). Qualitative study of mechanical parameters of conventional diagnostic $X$-ray machines in Mizoram. Radiological Physics and Technology, 11, 274-83. doi: 10.1007/s12194-018-0464-3

10. Turner, J.E. (2005). Interaction of Ionizing Radiation with Matter. Health Physics, 88(6), 520544 .

11. International Atomic Energy Agency (2014). Diagnostic Radiology Physics: A Handbook for Teachers and Students. 1400 Vienna, Austria.

12. Operator Manual 451P (2013). Ion Chamber 
Survey Meter, PN FBC-0059, Rev 1, Fluke Corporation, USA. flukebiomedical.com/biomedical/ usen/radiation-safety/survey-meters/451p-radiationdetector-ion-chamber-survey-meter.htm?pid=54793 (9 August 2018).

13. Sonawane, A.U., Meghraj, S., Sunil, K.J.V.K., Kulkarni, A., Shirva, V.K. \& Pradhan, A.S. (2010). Radiological safety status and quality assurance audit of medical X-ray diagnostic installations in India. Journal of Medical Physics, 35(4), 229-234. doi: 10.4103/0971-6203.71764

14. Vlachos, I., Tsantilas, X., Kalyvas, N., Delis, H., Kandarakis, I. \& Panayiotakis, G. (2015) Measuring scatter radiation in diagnostic X-rays for radiation protection purposes. Radiation Protection Dosimetry, 165(1-4), 382-385. doi: 10.1093/rpd/ncv093
15. Tsalafoutas, I.A. (2006). Excessive leakage radiation measured on two mobile $X$-ray units due to the methodology used by the manufacturer to calculate and specify the required tube shielding. The British Journal of Radiology, 79, 162-164. doi: 10.1259/bjr/17920806

16. What makes lead good for radiation shielding? Canada Metal, 8271 Lafrenaie, Montreal, Quebec. canadametal.com/lead-good-for-radiation-shielding (5 April 2019).

17. Archer, B.R. \& Gray, J.E. (2005). Important changes in medical X-ray imaging shielding design methodology. A brief summary of recommendations in NCRP Report No. 147. Medical Physics, 32(12), 3599-3601. doi: $10.1118 / 1.2124587$

\section{Supplementary data}

Figure 6 | Percentage of attenuation; attenuated by lead, concrete, plywood and plywood-plan sheet-lined barriers.

\begin{tabular}{clcccc}
\hline $\begin{array}{c}\text { No of } \\
\text { Units }\end{array}$ & $\begin{array}{c}\text { Type of } \\
\text { Units }\end{array}$ & Model of Units & $\begin{array}{c}\text { Year of } \\
\text { Installations }\end{array}$ & Type of Door & Type of Barrier \\
\hline 1 & $F^{\text {a }}$ & Heliophos-D & 1993 & Solid wood & Lead-lined \\
\hline 2 & F & DIAGNOX-300 & 2003 & Solid wood & Concrete \\
\hline 3 & F & ME-3010 & 2008 & Plywood & Lead-lined \\
\hline 4 & F & DX-525 & 2004 & Lead-lined & Lead-lined \\
\hline 5 & F & DX-300 & 2014 & Plywood & Lead-lined \\
\hline 6 & F & Allengers 325 & 2016 & Solid wood & Lead-lined \\
\hline 7 & MF & Multimobil 10 & 2008 & Plywood Plane sheet- & Plywood plane sheet- \\
& & lined & Plywood & Plywood \\
\hline 8 & MF & Genius 60 & 2012 & Plywood & Plywood \\
\hline 10 & MF & DIAGNOX-60 & 2007 & Solid wood & Lead-lined \\
\hline
\end{tabular}

${ }^{\text {a }}$ fixed $X$-ray $\quad{ }^{b}$ mobile $X$-ray which were installed in a room and used as fixed $X$-ray

Table 7 | Exposure rates outside PED with door and without door.

\begin{tabular}{|lllcccc}
\hline \multicolumn{2}{c}{ Parameters } & N & $\begin{array}{c}\text { Range } \\
(\mathbf{m R / h})\end{array}$ & $\begin{array}{c}\text { Minimum } \\
(\mathbf{m R / h})\end{array}$ & $\begin{array}{c}\text { Maximum } \\
(\mathbf{m R / h})\end{array}$ & $\begin{array}{c}\text { Mean } \\
(\mathbf{m R} / \mathbf{h})\end{array}$ \\
\hline Chest Mission & With Door & 10 & 69.96 & 0.03 & 70 & 18.95 \\
\cline { 2 - 7 } & Without door & 10 & 117.9 & 2.10 & 120 & 54.96 \\
\hline \multirow{2}{*}{ Couch Mission } & With Door & 10 & 219.96 & 0.03 & 220 & 43.44 \\
\cline { 2 - 8 } & Without Door & 10 & 222.2 & 2.8 & 225 & 74.73 \\
\hline
\end{tabular}

Table 8 | Exposure rates at CP with and without protective barriers.

\begin{tabular}{lllccccc}
\hline \multicolumn{2}{c}{ Parameters } & N & $\begin{array}{c}\text { Range } \\
(\mathbf{m R / h})\end{array}$ & $\begin{array}{c}\text { Minimum } \\
(\mathbf{m R / h})\end{array}$ & $\begin{array}{c}\text { Maximum } \\
(\mathbf{m R / h})\end{array}$ & $\begin{array}{c}\text { Mean } \\
(\mathbf{m R / h})\end{array}$ \\
\hline \multirow{2}{*}{ Chest Mission } & With Barriers & 10 & 37.8 & 0.2 & 38 & 10.56 \\
\cline { 2 - 8 } & Without Barriers & 10 & 195 & 40 & 235 & 113.1 \\
\hline \multirow{2}{*}{ Couch Mission } & With Barriers & 10 & 59.6 & 0.4 & 60 & 17.21 \\
\cline { 2 - 8 } & Without Barriers & 10 & 430 & 70 & 500 & 266.5 \\
\hline
\end{tabular}

